\title{
西藏东部高寒草甸苔蘚植物群落数量分类与排序
}

\author{
田悦, 赵正武, 刘艳* \\ 重庆师范大学, 生命科学学院, 重庆 401331
}

摘要: 为探讨高寒草甸苔藓植物群落分布格局及其与环境因子之间的关系, 按网格法在西藏东部的林芝市和昌都市设置了 28 个高寒草甸样地, 采用双向指示种分析 (TWINSPAN)、除趋势对应分析 (DCA) 和典范对应分析 (CCA) 的方法对群落进行数量 分类和排序。结果显示, 共记录有苔藓植物 19 科 30 属 60 种, 均为藓类植物; 其中, 丛藓科和真藓科的物种数占总种数的 $55 \%$ 。 群落优势种为北地对齿藓 (Didymodon fallax)、垂枝藓 (Rhytidium rugosum)、山羽藓 ( Abietinella abietina)、厚角绢藓 ( Entodon concinnus)、尖叶对齿藓芒尖变种 (Didymodon constrictus var. flexicuspis) 和短叶对齿藓(Didymodon tectorus)。根据 TWINSPAN 分 析结果可将西藏东部高寒草甸苔藓植物群落划分为 9 个群丛, 分别为沙氏真藓 (Bryum sauteri) 群丛、细枝羽藓 (Thuidium delicatulum $)+$ 狭网真藓 $($ Bryum algovicum $)+$ 羽枝青藓 $($ Brachythecium plumosum $)$ 群丛、尖叶对齿藓芒尖变种群丛、山羽藓+厚角绢 藓+垂枝藓群丛、扭口藓 (Barbula unguiculata) +垂枝藓+山羽藓群丛、垂枝藓+曲尾藓 ( Dicranum scoparium) 群丛、厚角绢藓群丛、 北地对齿藓群丛、短叶对齿藓群丛,分类结果反映了群丛类型与环境之间的关系。CCA 分析结果表明,影响西藏东部高寒草甸 苔藓植物群落分布的首要环境因子是纬度, 其次是归一化植被指数 (NDVI), 再次是黏土比例, 海拔和太阳辐射也有一定影响。 关键词:藓类植物; 青藏高原; 高寒草甸;分布格局;群落特征

\section{Classification and ordination of bryophyte communities in alpine meadow of eastern Tibet}

TIAN Yue, ZHAO Zhengwu, LIU Yan*

College of Life Sciences, Chongqing Normal University, Chongqing 401331, China

\begin{abstract}
To explore the distribution pattern of bryophyte communities in the alpine meadow and their relationships with environmental factors in eastern Tibet, 28 sample plots were set up in Nyingchi and Changdu based on the grid sampling method. Two-way indicator species analysis ( TWINSPAN), detrended correspondence analysis (DCA) and canonical correspondence analysis (CCA) were applied to the quantitative classification and ordination of bryophyte communities. The results showed that 60 species of bryophytes in 30 genera and 19 families were recorded, which all belonged to mosses. The number of species belonging to Pottiaceae and Bryaceae accounted for 55\% of the total species richness. The dominant species of the communities were Didymodon fallax, Rhytidium rugosum, Abietinella abietina, Entodon concinnus, Didymodon constrictus var. flexicuspis, and Didymodon tectorus. According to the TWINSPAN analysis, bryophyte communities were classified into nine associations (i. e. Bryum sauteri association, Thuidium delicatulum + Bryum algovicum + Brachythecium plumosum association, Didymodon constrictus var. flexicuspis association, Abietinella abietina+ Entodon concinnus + Rhytidium rugosum association, Barbula unguiculata + Rhytidium rugosum + Abietinella abietina association, Rhytidium rugosum + Dicranum scoparium, Entodon concinnus association, Didymodon fallax association,
\end{abstract}

基金项目:重庆市教委科学技术研究项目(KJQN201900549)

收稿日期: 2020-12-18; 网络出版日期:2021-09- 10

* 通讯作者 Corresponding author.E-mail: tracy-moss@ hotmail.com 
Didymodon tectorus association), which reflected the relationships between vegetation types and the environmental factors. CCA analysis revealed that latitude was the predominant environmental factor, followed by Normalized Vegetation Index ( NDVI), percentage of soil clay, influencing the distribution pattern of bryophyte communities in the alpine meadow of eastern Tibet. In addition, altitude and solar radiation were the other two environmental factors which significantly affected the distribution pattern of bryophyte communities.

Key Words: mosses; Qinghai-Tibetan Plateau; alpine meadow; distribution pattern; community characteristic

数量分类与排序是群落生态学研究的基本问题之一, 是系统描述植被特征的有效手段,能够客观揭示植 被与环境因子间的生态关系 ${ }^{[1]}$ 。研究植物群落分类与排序对于全面弄清区域植被特征具有重要科学价值, 有利于保护生物多样性和生态系统功能 ${ }^{[2]}$ 。苔藓植物物种多样性在高等植物中仅次于被子植物 ${ }^{[3]}$, 是植被 的重要组成成分,在土壤形成、水土保持、全球碳氮循环、植被恢复和重建等方面发挥着重要的生态功能 ${ }^{[4-6]}$ 。 然而, 目前关于苔藓植物群落分类与排序的研究, 多聚焦森林植被 ${ }^{[7-8]}$, 鲜有针对草地、尤其是高寒草地的 研究 $^{[9-11]}$ 。

草地是我国陆地上面积最大的生态系统, 对于保护生物多样性、保持水土、维护生态平衡具有重要价 值 ${ }^{[12]}$ 。西藏的天然草地面积位居全国第一。其中, 又以高寒草甸分布最广 ${ }^{[13]}$, 在我国草地类型中具有代表 性和独特性, 是西藏生态安全屏障的重要组成部分, 也是区域牧业经济发展的基础 ${ }^{[14]}$ 。研究表明, 苔藓植物 在高寒草甸群落演替过程中发挥着重要作用 ${ }^{[15-17]}$, 其抗寒能力比灌木、草本植物和萍类植物都要强 ${ }^{[18]}$ 。

本文以西藏东部高寒草甸的苔藓植物群落为研究对象, 在较大空间范围取样, 应用双向指示种分析 (Two-Way Indicator Species Analysis,TWINSPAN)、除趋势对应分析 (Detrended Correspondence Analysis, DCA) 和典范对应分析 (Canonical Correspondence Analysis, CCA), 进行数量分类和排序, 旨在探讨以下科学问题: (1) 西藏东部高寒草甸苔藓植物群落物种组成的特点; (2) 西藏东部高寒草甸苔藓植物群落的群丛类型; (3) 影响高寒草甸苔藓植物群落分布的主要环境因子, 以期为高寒植被研究和生物多样性保护提供本底资料和科 学依据。

\section{1 研究区与研究方法}

\section{1 研究区概况}

西藏东部高寒草甸位于昌都和林芝地区, 地理坐标 $92^{\circ} 34^{\prime} \mathrm{E}-97^{\circ} 21^{\prime} \mathrm{E}, 29^{\circ} 35^{\prime} \mathrm{N}-31^{\circ} 28^{\prime} \mathrm{N}$ 。气候寒冷, 相 对湿润。年平均温度约 $-4-4^{\circ} \mathrm{C}$, 年降水量 200-400 mm, 年蒸发量 1500-2000 $\mathrm{mm}$ 。植被以小嵩草高寒草甸 为主, 草群密集, 草层低矮。群落物种组成较为丰富, 以中生高山草类为主, 常见的伴生种有: 矮嵩草 (Kobresia humilis)、线叶嵩草 $(K$. capillifolia $) 、$ 四川嵩草 $(K$. setchwanensis $) 、$ 日喀则嵩草 (K. prainii)、短轴嵩草 $(K$. prattii) 等。土壤以高山草甸土为主。

\section{2 样方调查}

于 2019 年植被生长季的 7-8 月,采用样方法对西藏东部林芝和昌都地区开展高寒草甸苔藓植物调查。 基于中国植被类型分布图 ${ }^{[19]}$ 采取网格法设置样地, 即在经纬度 $0.5^{\circ} \times 0.5^{\circ}$ (约 $55.5 \mathrm{~km} \times 47.5 \mathrm{~km}$ ) 范围内随机 设置 1 个天然草地样地,样地大小为 $200 \mathrm{~m} \times 200 \mathrm{~m}$, 共 28 个(图 1)。样地所处海拔区间为 $2185-4658 \mathrm{~m}$, 南 北跨度 $179.67 \mathrm{~km}$, 东西跨度 $521.15 \mathrm{~km}$ 。使用 $20 \mathrm{~cm} \times 20 \mathrm{~cm}$ 的透明塑料板作为样方框, 在每个样地内设置样 方 5-8 个。样方框内部按照 $2 \mathrm{~cm} \times 2 \mathrm{~cm}$ 的大小又被细分为 100 个小方格。记录和采集样方中苔藓植物的物 种和方格数, 用物种所占方格数作为盖度数据。共调查样方 148 个, 采集苔藓植物标本 157 份。所有标本带 回实验室使用显微镜鉴定到种 ${ }^{[20]}$ 。凭证标本保存在重庆师范大学生物标本馆 (CTC)。

环境因子共 12 个,包括纬度、经度、海拔、年均降水量、年均蒸散发量、年均温度、年均太阳辐射、年均风 


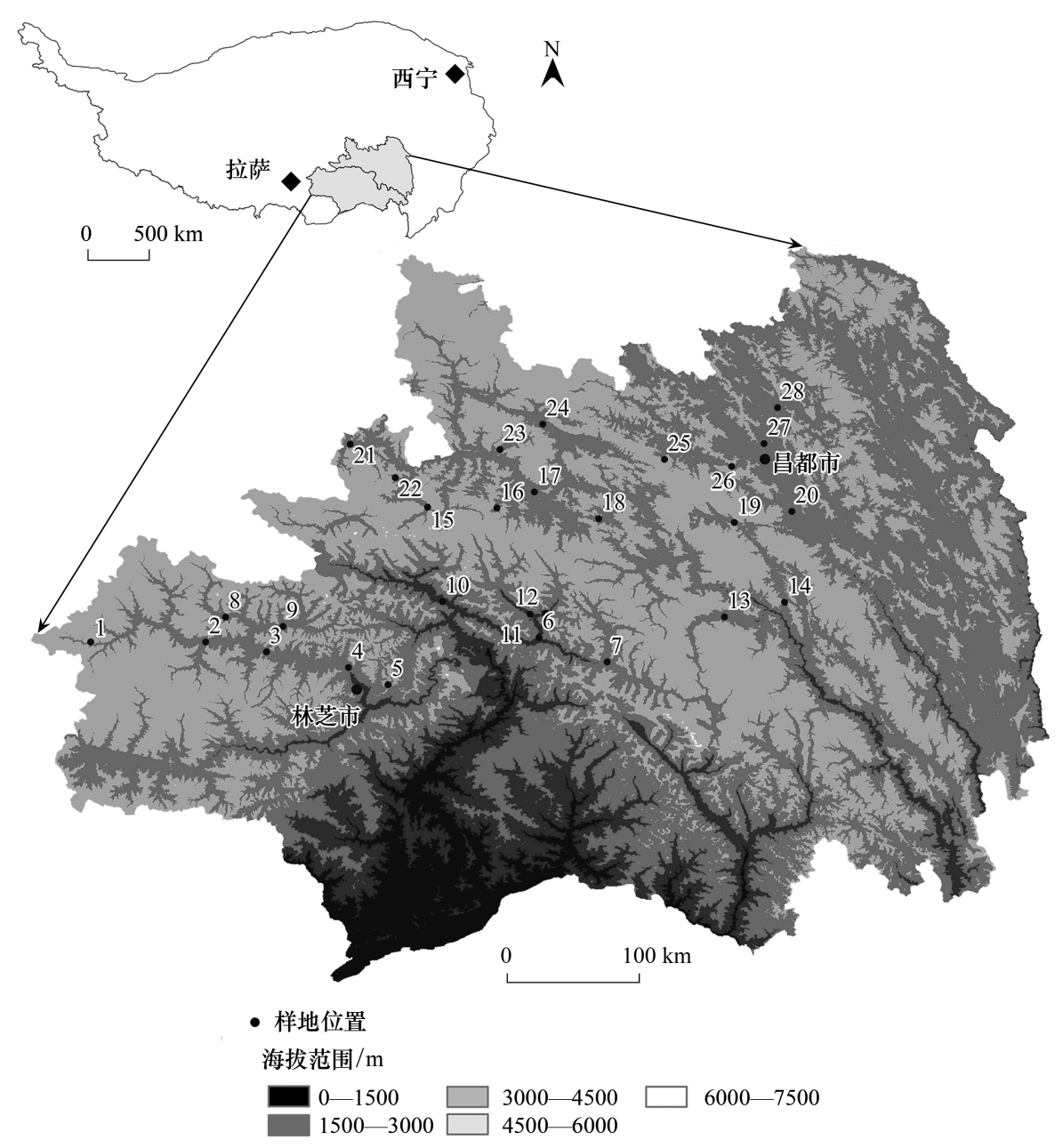

图 1 研究区及样地地理位置

Fig.1 The location of study area and the investigated plots 图中数字 1-28 代表样地编号

速、坡度、坡向、土壤质地和归一化植被指数 (Normalized Vegetation Index, NDVI)。根据手持 GPS 记录样地的 经纬度和海拔。气候数据来自全球气候数据 WorldClim 2.1 版 ${ }^{[21]}$, 时间跨度是 1970-2000 年, 空间分辨率为 $1 \mathrm{~km}^{2}$ 。年均蒸散发量来自中国陆地实际蒸散发数据集 ${ }^{[22]}$, 空间分辨率为 $0.1^{\circ}$ 。坡度、坡向和土壤质地数据 来源于中国科学院资源环境科学数据中心 (http://www.resdc.cn), 空间分辨率为 $1 \mathrm{~km}$ 。NDVI 数据来自 2018 年中国年度植被指数空间分布数据集 ${ }^{[23]}$, 空间分辨率为 $1 \mathrm{~km}$ 。以上数据集借助 ArcGIS Pro 软件提取样地对 应的环境数据。

\section{3 数据处理}

根据苔藓植物相对盖度和相对频度计算重要值 (importance value, IV ${ }^{[24]}$, 公式如下:

重要值 $(I V)=($ 相对盖度 + 相对频度 $) / 2$

群落分类和排序使用重要值数据。应用 WinTWINS2.3 软件进行 TWINSPAN 分析, 对苔藓植物群落进行 群丛类型划分, 并结合群丛内的优势种和指示种对群丛进行命名。软件参数设置: 假种切割水平为 6 级, 分别 是重要值为 $0 、 0.08 、 0.16 、 0.24 、 0.32$ 和 0.58 , 各级指示种的指示潜力值分别为 $0 、 0 、 1 、 1 、 1$ 和 1 , 即指示种的重 要值不小于 0.16 。群落排序使用 Rstudio1.3 软件的 vegan 程序包, 先对物种在各样地的重要值矩阵数据进行 DCA 排序, 然后根据 DCA 排序轴的梯度长度选择适宜的排序方法, 探讨苔藓植物物种和群落分布与环境因 子间的关系。使用 vegan 程序包中的 decostand 函数对物种重要值和环境数据进行 Z-score 标准化处理。 


\section{2 结果与分析}

\section{1 群落物种组成}

在所调查的 28 个高寒草甸样地中,共记录苔藓植物 19 科 30 属 60 种,均为藓类植物。主要由丛藓科 (8 属 18 种) 和真藓科(2 属 15 种)组成,占物种总数的 $55 \%$ 。根据物种重要值降序排序 (表 1 ), 西藏东部高寒草 甸苔藓植物群落的优势种 (取物种总数的 $10 \%$ ) 分别是北地对齿藓 (Didymodon fallax)、垂枝藓 (Rhytidium rugosum)、山羽藓 (Abietinella abietina)、厚角绢藓 (Entodon concinnus)、尖叶对齿藓芒尖变种 (Didymodon constrictus var. flexicuspis) 和短叶对齿藓 (Didymodon tectorus)。仅出现 1 次的偶见种有曲尾藓 (Dicranum scoparium)、钝叶芦荟藓(Aloina rigida) 和弯叶青藓(Brachythecium reflexum)等 31 种。

表 1 苔藓植物物种的相对盖度、相对频度和重要值

Table 1 Relative coverage and frequency and importance value of bryophyte species

\begin{tabular}{|c|c|c|c|c|}
\hline $\begin{array}{c}\text { 物种编号 } \\
\text { No. }\end{array}$ & $\begin{array}{l}\text { 物种名 } \\
\text { Species name }\end{array}$ & $\begin{array}{c}\text { 相对盖度 } \\
\text { Relative coverage }\end{array}$ & $\begin{array}{c}\text { 相对频度 } \\
\text { Relative frequency }\end{array}$ & $\begin{array}{c}\text { 重要值 } \\
\text { Importance value }\end{array}$ \\
\hline S1 & 北地对齿藓 Didymodon fallax & 2.550 & 3.324 & 2.937 \\
\hline S2 & 垂枝藓 Rhytidium rugosum & 1.870 & 3.728 & 2.799 \\
\hline S3 & 山羽藓 Abietinella abietina & 2.152 & 2.896 & 2.524 \\
\hline S4 & 厚角绢藓 Entodon concinnus & 1.534 & 2.146 & 1.840 \\
\hline S5 & 尖叶对齿藓芒尖变种 Didymodon constrictus var. flexicuspis & 1.934 & 1.506 & 1.720 \\
\hline S6 & 短叶对齿藓 Didymodon tectorus & 0.984 & 1.116 & 1.050 \\
\hline S7 & 细枝羽藓 Thuidium delicatulum & 0.459 & 1.129 & 0.794 \\
\hline S8 & 近高山真藓 Bryum alpinum & 0.951 & 0.603 & 0.777 \\
\hline S9 & 沙氏真藓 Bryum sauteri & 0.599 & 0.667 & 0.633 \\
\hline S10 & 扭口藓 Barbula unguiculata & 0.670 & 0.572 & 0.621 \\
\hline S11 & 节茎曲柄藓 Campylopus umbellatus & 0.611 & 0.599 & 0.605 \\
\hline $\mathrm{S} 12$ & 灰藓 Hypnum cupressiforme & 0.666 & 0.500 & 0.583 \\
\hline S13 & 绢藓 Entodon cladorrhizans & 0.499 & 0.647 & 0.573 \\
\hline $\mathrm{S} 14$ & 真藓 Bryum argenteum & 0.532 & 0.592 & 0.562 \\
\hline $\mathrm{S} 15$ & 刺叶真蘚 Bryum lonchocaulon & 0.633 & 0.449 & 0.541 \\
\hline S16 & 土生对齿蘚 Didymodon vinealis & 0.534 & 0.460 & 0.497 \\
\hline S17 & 曲尾藓 Dicranum scoparium & 0.617 & 0.271 & 0.444 \\
\hline S18 & 青藓 Brachythecium pulchellum & 0.533 & 0.339 & 0.436 \\
\hline S19 & 红对齿藓 Didymodon asperifolius & 0.451 & 0.375 & 0.413 \\
\hline S20 & 高山赤藓 Syntrichia sinensis & 0.450 & 0.352 & 0.401 \\
\hline $\mathrm{S} 21$ & 羽枝青藓 Brachythecium plumosum & 0.458 & 0.340 & 0.399 \\
\hline S22 & 多褶青藓 Brachythecium buchananii & 0.333 & 0.403 & 0.368 \\
\hline $\mathrm{S} 23$ & 丛生真藓 Bryum caespiticium & 0.449 & 0.245 & 0.347 \\
\hline $\mathrm{S} 24$ & 葫芦藓 Funaria hygrometrica & 0.300 & 0.386 & 0.343 \\
\hline S25 & 狭网真蘚 Bryum algovicum & 0.417 & 0.249 & 0.333 \\
\hline S26 & 细叶真藓 Bryum capillare & 0.300 & 0.308 & 0.304 \\
\hline S27 & 红叶藓 Bryoerythrophyllum recurvirostrum & 0.325 & 0.281 & 0.303 \\
\hline S28 & 垂蒴真蘚 Bryum uliginosum & 0.409 & 0.185 & 0.297 \\
\hline S29 & 双色真藓 Bryum dichotomum & 0.250 & 0.328 & 0.289 \\
\hline $\mathrm{S} 30$ & 弯叶青藓 Brachythecium reflexum & 0.251 & 0.319 & 0.285 \\
\hline $\mathrm{S} 31$ & 溪边对齿藓 Didymodon rivicola & 0.334 & 0.186 & 0.260 \\
\hline $\mathrm{S} 32$ & 反扭藓 Timmiella anomala & 0.200 & 0.306 & 0.253 \\
\hline S33 & 净口藓 Gymnostomum calcareum & 0.167 & 0.295 & 0.231 \\
\hline S34 & 黄色真蘚 Bryum pallescens & 0.334 & 0.094 & 0.214 \\
\hline $\mathrm{S} 35$ & 小扭口藓 Barbula indica & 0.166 & 0.238 & 0.202 \\
\hline S36 & 拟扭口藓 Barbula pseudo-ehrenbergii & 0.223 & 0.159 & 0.191 \\
\hline $\mathrm{S} 37$ & 皱叶匐灯藓 Plagiomnium arbusculum & 0.166 & 0.212 & 0.189 \\
\hline
\end{tabular}




\begin{tabular}{|c|c|c|c|c|}
\hline $\begin{array}{c}\text { 物种编号 } \\
\text { No. }\end{array}$ & $\begin{array}{l}\text { 物种名 } \\
\text { Species name }\end{array}$ & $\begin{array}{c}\text { 相对盖度 } \\
\text { Relative coverage }\end{array}$ & $\begin{array}{c}\text { 相对频度 } \\
\text { Relative frequency }\end{array}$ & $\begin{array}{c}\text { 重要值 } \\
\text { Importance value }\end{array}$ \\
\hline S38 & 对叶蘚 Distichium capillaceum & 0.200 & 0.170 & 0.185 \\
\hline S39 & 淡色同叶蘚 Isopterygium albescens & 0.167 & 0.159 & 0.163 \\
\hline $\mathrm{S} 40$ & 球蒴真藓 Bryum turbinatum & 0.284 & 0.036 & 0.160 \\
\hline $\mathrm{S} 41$ & 长尖对齿蘚 Didymodon ditrichoides & 0.250 & 0.058 & 0.154 \\
\hline $\mathrm{S} 42$ & 直叶紫荌藓 Grimmia elatior & 0.111 & 0.181 & 0.146 \\
\hline $\mathrm{S} 43$ & 粗齿鲁灯藓 Plagiomnium drummondii & 0.210 & 0.082 & 0.146 \\
\hline S44 & 小石蘚 Weissia controversa & 0.249 & 0.041 & 0.145 \\
\hline S45 & 韩氏真蘚 Bryum blandum & 0.201 & 0.061 & 0.131 \\
\hline S46 & 大曲背藓 Oncophorus virens & 0.199 & 0.041 & 0.120 \\
\hline S47 & 泛生墙蘚 Tortula muralis & 0.167 & 0.029 & 0.098 \\
\hline $\mathrm{S} 48$ & 毛梳藓 Ptilium crista-castrensis & 0.084 & 0.106 & 0.095 \\
\hline S49 & 拟垂枝藓 Rhytidiadelphus squarrosus & 0.084 & 0.106 & 0.095 \\
\hline S50 & 钝叶芦荟蘚 Aloina rigida & 0.100 & 0.080 & 0.090 \\
\hline S51 & 木灵藓 Orthotrichum anomalum & 0.166 & 0.012 & 0.089 \\
\hline S52 & 大帽蘚 Encalypta ciliata & 0.125 & 0.049 & 0.087 \\
\hline S53 & 短月藓 Brachymenium nepalense & 0.125 & 0.045 & 0.085 \\
\hline S54 & 尖叶对齿蘚 Didymodon constrictus & 0.100 & 0.070 & 0.085 \\
\hline S55 & 拟大叶真蘚 Bryum salakense & 0.126 & 0.020 & 0.073 \\
\hline S56 & 极地真藓 Bryum arcticum & 0.099 & 0.035 & 0.067 \\
\hline S57 & 曲柄蘚 Campylopus flexuosus & 0.100 & 0.020 & 0.060 \\
\hline S58 & 皱叶连轴蘚 Schistidium subconfertum & 0.099 & 0.019 & 0.059 \\
\hline S59 & 黑对齿蘚 Didymodon nigrescens & 0.110 & 0.004 & 0.057 \\
\hline S60 & 毛尖棉藓 Plagiothecium piliferum & 0.099 & 0.007 & 0.053 \\
\hline
\end{tabular}

\section{2 群落分类}

TWINSPAN 经过 6 次聚类,将 28 个样地划分为 9 个群丛(图 2)。各群丛主要环境因子见表 2 。

划分各个分类水平的指示种分别是: (1) 葫芦藓 (Funaria hygrometrica) (3+); (2) 北地对齿藓 (4-)、垂枝 藓 (3+)、短叶对齿藓 (4-); (3) 短叶对齿藓 (3-); (4) 细枝羽藓 (Thuidium delicatulum) (3+)、山羽藓 (3-)、垂 枝蘚 (3-)、短叶对齿藓 $(3+)$ 、厚角绢藓 $(3-)$; (5) 多褶青鲭 (Brachythecium buchananii) $(3+)$; (6) 垂枝藓 $(5-)$; (7) 厚角绢藓 $(3-)$; (8) 山羽藓 (3+)、高山赤藓 (Syntrichia sinensis) (3-)、厚角绢藓 $(3+)$ 。

群丛 1 : 沙氏真藓 (Bryum sauteri) 群丛, 伴生种有葫芦藓和细叶真藓 (Bryum capillare)。包括 1 个样地 (19), 海拔 $4359 \mathrm{~m}$,位于昌都八宿县。该样地黏土比例最低。苔藓植物总平均盖度 $3 \%$ 。

群丛 2 : 细枝羽藓+狭网真藓 (Bryum algovicum) +羽枝青藓 (Brachythecium plumosum) 群丛, 伴生种有垂蒴 真藓 (Bryum uliginosum) 、山羽藓、厚角绢藓、短叶对齿藓、青藓 (Brachythecium pulchellum) 等 16 种。包括 4 个 样地 $(3 、 4 、 5 、 7)$, 其中 3 个位于林芝巴宜区, 1 个位于林芝波密县。年均降水量和黏土比例较高。苔藓植物总 平均盖度 $45.35 \%$ 。

群丛 3 : 尖叶对齿藓芒尖变种群丛, 伴生种有短叶对齿藓、刺叶真藓 (Bryum lonchocaulon)、直叶紫䓵藓 (Grimmia elatior)、多褶青藓、极地真藓(Bryum arcticum) 等 10 种。包括两个样地 ( 1 和 28 ), 分别位于林芝工 布江达县和昌都卡若区。平均年降水量最低, 而平均植被归一化指数最高。苔藓植物总平均盖度 $31.83 \%$ 。

群丛 4 : 山羽藓+厚角绢藓+垂枝藓群丛,伴生种有尖叶对齿藓芒尖变种、近高山真藓 (Bryum alpinum)、北 地对齿藓、丛生真蘚 (Bryum caespiticium)、青蘚等 14 种。包括 8 个样地 $(8 、 10 、 11 、 12 、 16 、 21 、 22 、 27)$, 主要在 林芝波密县和昌都边坝县。样地间的海拔跨度最大, 近 $2000 \mathrm{~m}$; 平均年降水量和平均植被归一化指数较高。 苔藓植物总平均盖度 $57.64 \%$ 。 


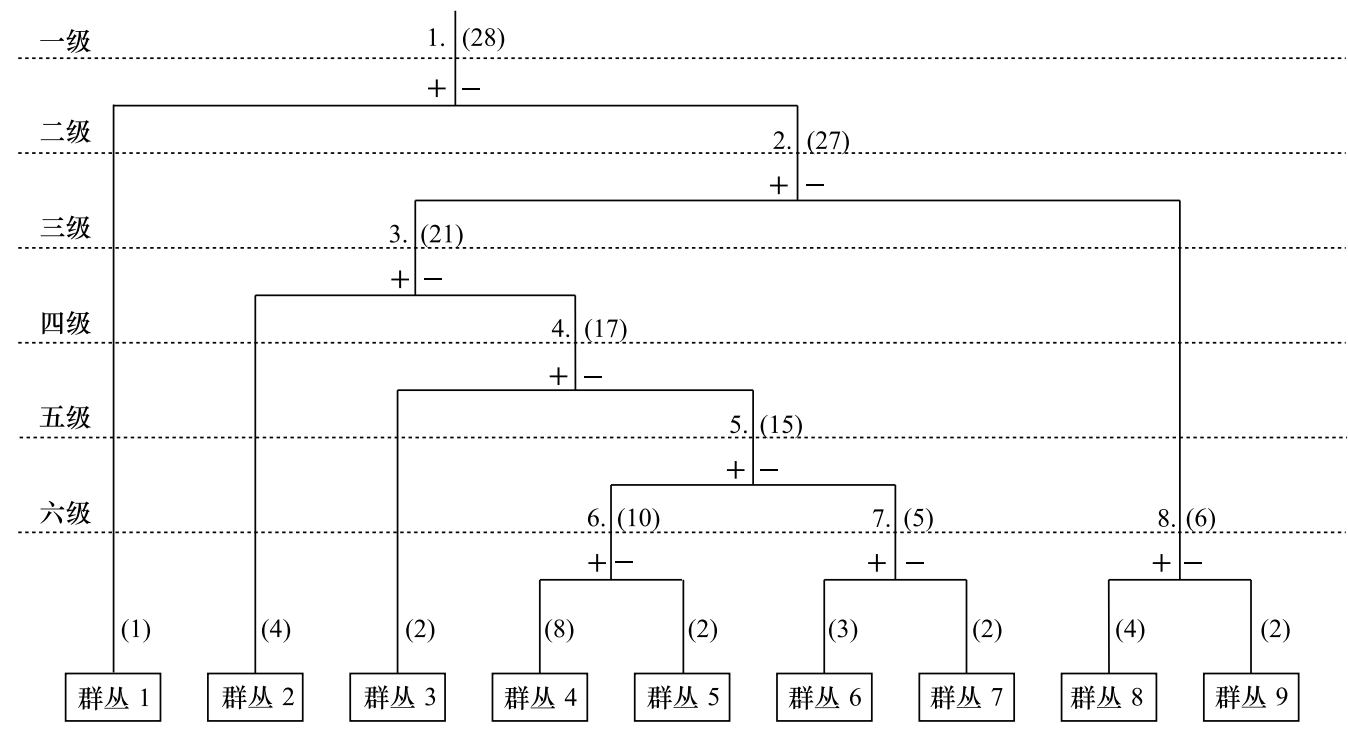

图 2 样地 TWINSPAN 分类树状图

Fig.2 Dendrogram of the TWINSPAN classification of 28 plots

级数表示分类水平数;数字表示分类次数;括号内数字表示该类包含的样地数

表 2 各群丛主要环境变量范围及平均值

Table 2 Range and average value of environmental variables of each associations

\begin{tabular}{|c|c|c|c|c|c|}
\hline $\begin{array}{c}\text { 群丛 } \\
\text { Association }\end{array}$ & $\begin{array}{l}\text { 海拔/m } \\
\text { Altitude }\end{array}$ & $\begin{array}{l}\text { 太阳辐射/ }\left(\mathrm{kJ} \mathrm{m}^{-2} \mathrm{~d}^{-1}\right) \\
\text { Solar radiation }\end{array}$ & $\begin{array}{l}\text { 年均降水量/mm } \\
\text { Mean annual } \\
\text { precipitation }\end{array}$ & $\begin{array}{l}\text { 植被归一化指数 } \\
\text { Normalized } \\
\text { vegetation Index }\end{array}$ & $\begin{array}{l}\text { 黏土比例 } / \% \\
\text { Percentage of clay }\end{array}$ \\
\hline 1 & $4359(4359)$ & 14977 ( 14977 ) & $583(583)$ & $0.54(0.54)$ & $14(14)$ \\
\hline 2 & $3002-4151(3350)$ & $15052-16366(15603)$ & $553-764(642)$ & $0.39-0.79(0.61)$ & $18-27(23.3)$ \\
\hline 3 & $3434-4161(3797)$ & $15109-16479(15794)$ & $440-521(480)$ & $0.67-0.80(0.74)$ & $17-22(19.5)$ \\
\hline 4 & $2185-4140(3356)$ & $15053-16136(15546)$ & $522-759(651)$ & $0.49-0.74(0.64)$ & $14-27(19.6)$ \\
\hline 5 & $3406-3468(3437)$ & $16020-16467(16244)$ & $512-586(549)$ & $0.54-0.77(0.66)$ & $22-25(23.5)$ \\
\hline 6 & $3667-4658(4212)$ & $14984-15666(15263)$ & $585-607(596)$ & $0.59-0.7(0.65)$ & $17-19(18)$ \\
\hline 7 & $3753-4610(4181)$ & $14748-15686(15217)$ & $610-615(612)$ & $0.53-0.75(0.65)$ & $14-25(20)$ \\
\hline 8 & $3314-4055(3803)$ & $15176-15867(15470)$ & $611-646(626)$ & $0.38-0.57(0.48)$ & $9-21(16)$ \\
\hline 9 & $2675-3110(2892)$ & $15093-15185(15139)$ & $555-827(691)$ & $0.4-0.5(0.45)$ & $22-23(22.5)$ \\
\hline
\end{tabular}

群丛 5: 扭口藓 (Barbula unguiculata) +垂枝藓 + 山羽藓群丛, 伴生种有短叶对齿藓、真藓 (Bryum argenteum)、直叶紫葶藓、尖叶对齿藓芒尖变种、粗齿匐灯藓 (Plagiomnium drummondii) 等 11 种。包括两个样 地 (2 和 9), 均在林芝工布江达县。平均年降水量较低, 而黏土比例最高、平均植被归一化指数较高。苔蘚植 物总平均盖度 $42.93 \%$ 。

群丛 6:垂枝藓+曲尾藓群丛, 伴生种有红对齿藓 (Didymodon asperifolius)、刺叶真蘚、灰藓 (Hypnum cupressiforme)、尖叶对齿藓芒尖变种、大曲背藓 (Oncophorus virens)、对叶藓 (Distichium capillaceum)、韩氏真蘚 (Bryum blandum)。包括 3 个样地 $(14 、 17 、 25)$, 分别在昌都八宿县、洛隆县、类乌齐县。样地平均海拔 $4212 \mathrm{~m}$, 平均年降水量较低,而平均植被归一化指数较高。苔藓植物总平均盖度 $40.13 \%$ 。

群丛 7 : 厚角绢藓群丛,伴生种有扭口藓、灰藓、真藓、大帽藓 (Encalypta ciliata) 等 8 种。包括两个样地 $(23$ 和 26), 分别在昌都丁青县和卡若区。样地平均海拔 $4181 \mathrm{~m}$, 平均年降水量和平均植被归一化指数较高。苔 藓植物总平均盖度 $43.56 \%$ 。

群丛 8: 北地对齿藓群丛,伴生种有垂蒴真藓、丛生真藓、黄色真藓 (Bryum pallescens)、弯叶青藓、溪边对齿 
藓 (Didymodon rivicola)、土生对齿藓 (Didymodon vinealis)、灰藓、近高山真藓。包括 4 个样地 $(13 、 15 、 18 、 24)$, 均位于昌都市南部四个县。样地平均海拔 $3803 \mathrm{~m}$, 平均年降水量较高, 而平均植被归一化指数和黏土比例较 低。苔藓植物总平均盖度 $12.69 \%$ 。

群丛 9:短叶对齿藓群丛,伴生种有北地对齿藓、土生对齿藓、红对齿蘚、扭口藓、青藓、刺叶真蘚。包括两 个样地 (6 和 20), 分别位于林芝波密县和昌都察雅县, 是平均海拔最低的群丛。平均年降水量最高, 而平均 植被归一化指数最低。苔藓植物总平均盖度 $55.4 \%$ 。

\subsection{CCA 排序}

DCA 排序轴的最大轴为 7.933(>4), 因此选用基于单峰模型的 CCA 进行直接排序。利用前向选择法剔 除穴余变量的方法,最终从 12 个环境因子中䇥选出 5 个对高寒草甸苔藓植物群落分布影响显著的环境因子 (表 3)。计算环境变量的方差膨胀因子, 其值均小于 3 , 说明没有明显的共线性问题。根据各环境因子的决 定系数 $R^{2}$ 值可知 (表 3), 纬度是首要环境因子, 其次是 NDVI, 再次是黏土比例, 海拔和太阳辐射也有一定 影响。

\section{表 3 基于 CCA 分析的显著环境因子}

Table 3 Significant environmental variables in canonical correspondence analysis (CCA)

\begin{tabular}{lrccc}
\hline $\begin{array}{l}\text { 环境变量 } \\
\text { Environmental variables }\end{array}$ & $\begin{array}{c}\text { 轴 } 1 \\
\text { CCA1 }\end{array}$ & $\begin{array}{c}\text { 轴 } 2 \\
\text { CCA2 }\end{array}$ & $\begin{array}{c}\text { 决定系数 } R^{2} \\
\text { Coefficient } \\
\text { determination }\end{array}$ & $\begin{array}{c}\text { 显著性 } \operatorname{Pr}(>r) \\
\text { Significance }\end{array}$ \\
\hline 纬度 Latitude & -0.196 & -0.980 & 0.840 & $0.001^{* * * *}$ \\
海拔 Altitude & 0.110 & -0.994 & 0.307 & $0.009^{* * *}$ \\
太阳辐射 Solar radiation & -0.795 & 0.606 & 0.246 & $0.029^{*}$ \\
归一化植被指数 Normalized Vegetation Index & -0.999 & -0.045 & 0.788 & $0.001^{* * *}$ \\
黏土比例 Percentage of soil clay & -0.235 & 0.972 & 0.490 & $0.001^{* * *}$ \\
\hline
\end{tabular}

$* * *$ 表示在 0.001 水平上显著, $* *$ 表示在 0.01 水平上显著, $*$ 表示在 0.05 水平上显著

对 28 个样地和 5 个显著环境因子的 CCA 排序结果见图 3。蒙特卡洛检验结果显示, 模型通过统计检验 $(P=0.015)$ 。5 个显著环境因子对物种分布的解释量为 $26.34 \%$ 。与 CCA 第一轴相关性最高的是 NDVI, 其次 是太阳辐射, 均呈负相关, 表明第一轴主要反映了植被覆盖度和太阳辐射的梯度变化。与 CCA 第二轴相关性 最高的是海拔,其次是纬度和黏土比例,表明第二轴主要反映了气候和土壤的梯度变化。

28 个样地被分成界限明显的四个生态区, $\mathrm{A}$ 区包括群丛 $2 、 8$ 和 9 的各 1 个样地,分布在研究区南部,群落 植被覆盖度最低、黏土比例较 C、D 区的群丛高。B 区包含群丛 $2 、 3 、 4$ 和 5 的大部分样地, 分布在研究区南部 海拔最低的区域,群落黏土比例最高, 植被覆盖度较 A、D 区的群丛高。C 区包含群丛 3、4、6 和 7 中的个别样 地, 分布在研究区北部海拔较高的区域,群落植被覆盖度较高而黏土比例较低。D 区包含群丛 $1 、 4 、 7 、 8$ 和 9 中的样地,分布在研究区北部海拔较高的草甸,群落植被覆盖度和黏土比例均较低。

对物种-环境进行 CCA 排序分析 (图 4), 可以看出物种的分布也可以分成 4 个区,并且其与图 3 中的 4 个 生态区基本重合, 说明在环境因子的作用下,物种分布反映群丛分布。 $\mathrm{A}$ 区中的物种,植被覆盖度是主要影响 因子, 如短叶对齿藓、红对齿藓、土生对齿藓、溪边对齿藓等都属于在植被覆盖度低的生境中聚集生长的丛藓 科物种。B 区水热条件最好, 分布的物种最多, 如粗齿匐灯藓、高山赤藓、毛尖棉藓 (Plagiothecium piliferum)、 毛梳藓 (Ptilium crista-castrensis)、拟垂枝藓( Rhytidiadelphus squarrosus)、山羽蘚等。C 区的生境条件则具有过 渡性, 分布的物种也是对水热条件要求不高的物种, 如大帽藓、淡色同叶藓 (Isopterygium albescens)、短月藓 (Brachymenium nepalense)、多褶青藓等。D 区纬度和海拔都较高, 水热条件最差, 如适应极端生境能力较强的 北地对齿藓分布在该区。分布在原点附近的则是适应性较强、分布较为广泛的物种, 如刺叶真藓、丛生真藓和 扭口蘚。 


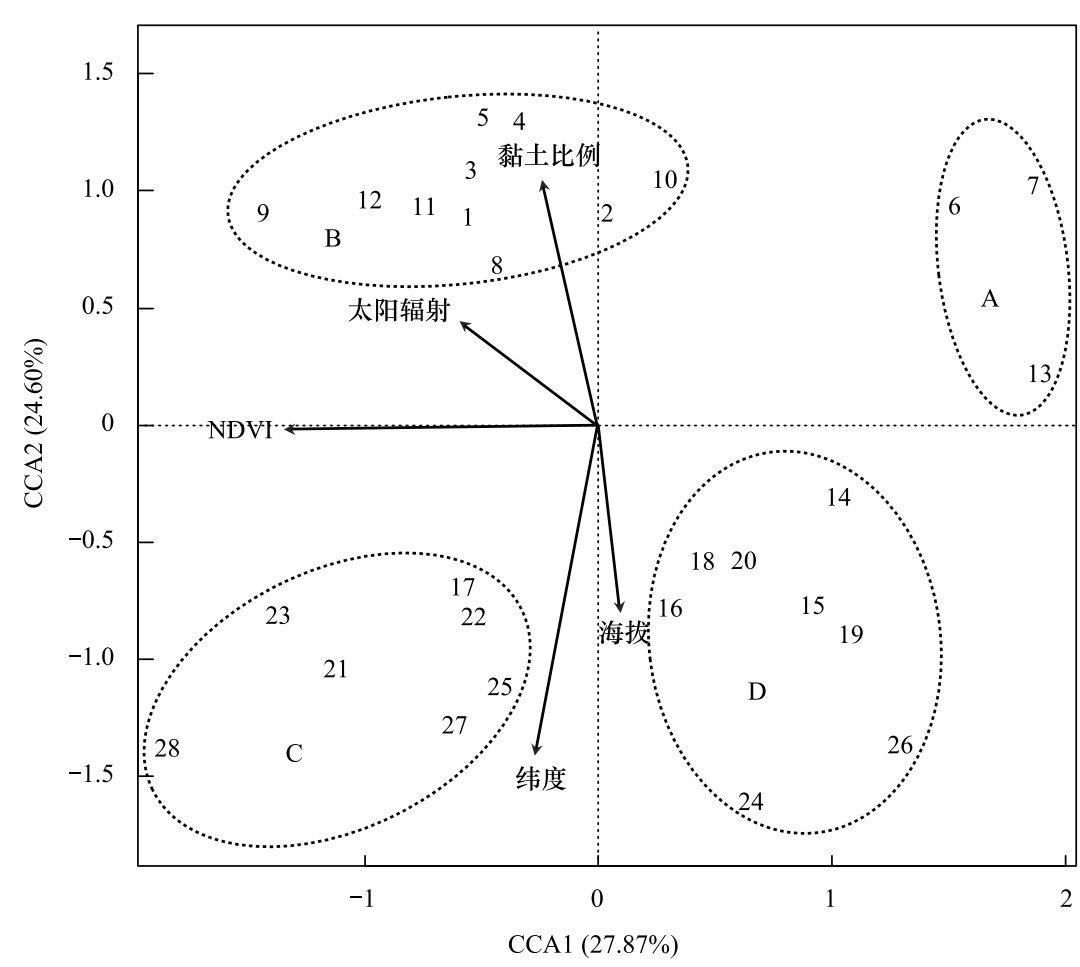

图 3 样地与环境因子典范对应分析 $(\mathrm{CCA})$ 排序图

Fig.3 Canonical Correspondence Analysis ( CCA) ordination diagram of 28 plots

NDVI : 归一化植被指数 Normalized Vegetation Index; $1-28$ 表示样地编号; A-D 表示样地在图中聚集的不同区域

\section{3 讨论}

目前, 国内基于大尺度空间范围的苔蘚植物群落分类与排序的研究较少, 仅有对西藏干旱与半干旱地区 丛藓科的专门研究 ${ }^{[10-11]}$ 。本研究范围南北跨度 $179.67 \mathrm{~km}$ 、东西跨度 $521.15 \mathrm{~km}$ 、垂直落差近 $2500 \mathrm{~m}$, 在较大空 间尺度上开展了高寒草甸苔藓植物群落数量生态学研究,进一步为草地植被研究提供了补充资料。结果显 示, 所有种类均属于藓类植物, 表明在西藏高寒草甸, 藓类植物占绝对优势。其中, 又以丛藓科的物种数目最 多。上述物种组成特点与西藏河谷区人工草地 ${ }^{[9]}$ 、祁连山草地 ${ }^{[25]}$ 、土耳其北部半干旱区 ${ }^{[26]}$ 的研究结果一致。 北地对齿藓是西藏东部高寒草甸的优势种之一。该种也是整个西藏及西藏不同草地类型中分布最广泛的丛 藓科种类 ${ }^{[10]}$; 并且, 优势种以对齿藓属物种为主 (占一半), 该属是典型的耐干旱藓类 ${ }^{[27]}$, 是干旱、半干旱地区 生物结皮的主要组成成分 ${ }^{[28-29]}$, 被认为是指示青藏高原气候变化的理想类群 ${ }^{[30]}$ 。本研究结果再次表明, 丛藓 科具有很强的适应极端环境的能力 ${ }^{[27,31]}$ 。此外, 群落偶见种占物种总数的 $50 \%$ 以上, 表明多数种类在西藏高 寒草甸中的分布范围较窄, 这可能是导致苔藓群丛类型差异的重要原因, 也从侧面证明了苔藓植物具有良好 的环境指示作用 ${ }^{[30,32-33]}$ 。

TWINSPAN 聚类分析将 28 个样地分成了 9 个群丛。从群丛的生境条件来看, 沙氏真藓群丛的黏土比例 最低, 细枝羽藓+狭网真藓+羽枝青藓群丛的纬度最低, 扭口藓+垂枝藓+山羽藓群丛黏土比例最高, 短叶对齿 藓群丛平均海拔最低而年平均温度最高, 表明群落分类结果良好, 环境梯度影响苔藓植物群落组成和群丛类 型的间断性。以丛藓科为主的尖叶对齿藓芒尖变种群丛、北地对齿藓群丛和短叶对齿藓群丛分布在水热条件 较差的区域,而对水热条件要求较高的细枝羽锌+狭网真藓+羽枝青藓群丛,垂枝藓+曲尾藓群丛和厚角绢藓 群丛则生长在植被覆盖度较高的区域, 可见苔藓植物群落类型较好地反映了高寒草甸环境条件的差异。结合 排序图 (图 3) 来看, 虽然各群落聚集在四个不同的生态区域, 但各群丛间并没有清晰的分界线, 这可能与西藏 


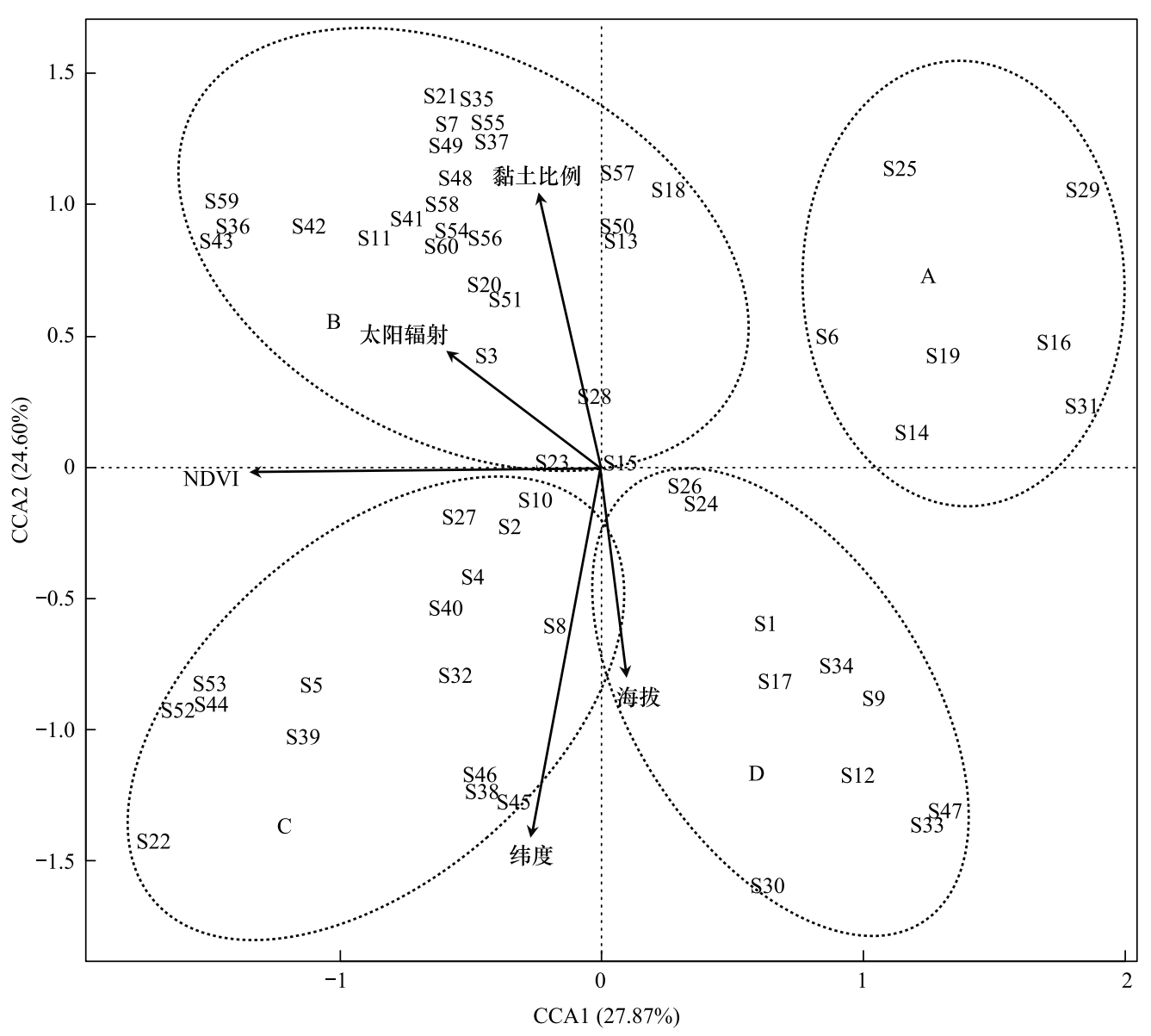

图 4 物种与环境因子 CCA 排序图

Fig.4 CCA ordination diagram of 60 species

$\mathrm{S} 1-\mathrm{S} 60$ 表示物种编号; $\mathrm{A}-\mathrm{D}$ 表示物种在图中聚集的不同区域

东部的横断山系和三江所构成的平行峡谷地貌 ${ }^{[34]}$ 形成的局部复杂小气候有关。

植物群落是生物与环境长时间复杂地相互作用和相互适应的结果。在高寒草甸植物群落, 已有报道认为 温度 ${ }^{[35]}$ 、海拔 ${ }^{[36-37]}$ 和土壤理化性质 ${ }^{[38-39]}$ 是影响群落分布的重要因子。这与本文得出的纬度、海拔和黏土比 例是影响苔藓植物群落分布的主要环境因子的研究结果一致。由于本文基于较大空间范围取样,纬度和海拔 作为环境变量, 其本质反映的是群落间水分、温度、土壤、太阳辐射等生态因子的复杂变化。在大尺度上,纬度 对苔藓植物物种组成的影响很大 ${ }^{[40-41]}$ 。此外, 土壤质地也会影响半干旱地区苔藓植物的分布 ${ }^{[26]}$ 。另一方面, 降水, 往往被认为是影响干旱与半干旱地区群落分布的重要因子 ${ }^{[31,42]}$, 然而, 本研究结果显示, 降水对高寒草 甸苔藓植物群落分布的影响并不显著, 这可能与苔藓植物属于变水植物有关 ${ }^{[6]}$, 以丛藓科等为代表的类群, 却能够在极端干旱环境下生存 ${ }^{[27,31]}$ 。本文所调查样地的年均降水量为 $440-827 \mathrm{~mm}$ (表 2), 相比草原或荒漠 草原等其它干旱、极端干旱的地区, 降水相对丰富。类似的, 基于西藏草地大尺度的研究结果发现, 在高寒地 区, 反映热量的环境因子对苔藓植物分布的影响大于水分因子 ${ }^{[10,30]}$ 。

本研究结果显示, NDVI 是显著影响高寒草甸苔藓植物群落的另一个重要环境因子(表 3 ), 这与影响西藏 草地对齿藓属分布的研究结果一致 ${ }^{[10]}$ 。NDVI 能有效的反映植被覆盖程度 ${ }^{[43]}$ 。有研究认为, 苔藓丰富度与 草地维管植物的覆盖度呈负相关 ${ }^{[4]}$; 也有研究认为, 二者呈正相关 ${ }^{[45]}$ 。从图 4 可以看出, 65\% (43/60) 的物 种与植被覆盖度呈正相关, 分布在植被覆盖度相对较高的高寒草甸群落中。这可能是因为维管植物不仅能在 一定程度上为更低矮的苔藓植物增加小生境的湿度, 而且能够增加小生境的温度 ${ }^{[45]}$ 。对西藏高寒人工草地 
的研究结果也认为, 小生境的温度和相对湿度对苔藓植物生长和分布影响较大 ${ }^{[9]}$ 。因此, NDVI 可能通过改 变小生境的水分和热量条件影响苔藓群落的分布。图 4 中以对齿藓属和真藓属为代表的、与植被覆盖度呈负 相关的物种可能是先锋种类, 在群落演替过程中起重要作用。值得注意的是, 温度会影响高寒草甸植被的覆 盖度 ${ }^{[46]}$ 。气候变暖、降水量的增加, 促进了青藏高原草地植被覆盖度的增加, 而放牧强度的增强则会导致草 地植被覆盖度的减少 ${ }^{[47]}$ 。因此,气候变化和放牧强度对高寒草甸植被覆盖度的影响, 最终也将决定高寒草甸 苔藓群落未来分布格局的变化。

本文所选的环境因子对高寒草甸苔藓植物群落分布的环境解释量只有 $26.34 \%$,这可能与目前考虑的环

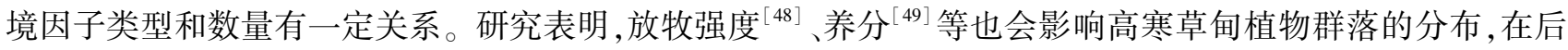
续的研究中将考虑更多不同类型的环境因子, 以便更好的揭示高寒草甸苔藓植物群落分布及其环境驱动 机制。

致谢: 感谢中国科学院地理与资源环境研究所何念鹏研究员、李明旭博士和中国科学院青藏高原研究所丁金 枝副研究员、曹荣芳博士以及第二次青藏科考生物地球化学循环与环境健康科考分队李超博士和蔡伟祥同学 在野外群落调查工作中给予的帮助。

\section{参考文献( References) :}

[ 1 ] 张金屯. 数量生态学(第三版). 北京: 科学出版社, 2018.

[ 2 ] Guo K, Liu C C, Xie Z Q, Li F Y, Franklin S B, Lu Z J, Ma K P. China vegetation classification: concept, approach and applications. Phytocoenologia, 2018, 48(2): 113-120.

[ 3 ] Goffinet B, Shaw A J. Bryophyte Biology. 2nd ed. Cambridge: Cambridge University Press, 2009.

[ 4 ] 吴玉环, 程国栋, 高谦. 苔藓植物的生态功能及在植被恢复与重建中的作用. 中国沙漠, 2003, 23(3): 215-220.

[ 5 ] 田维莉, 孙守琴. 苔藓植物生态功能研究新进展. 生态学杂志, 2011, 30(6) : 1265-1269.

[ 6 ] Tuba Z, Slack N G, Stark L R. Bryophyte Ecology and Climate Change. Cambridge: Cambridge University Press, 2011.

[ 7 ] 郭水良, 曹同. 长白山地区森林生态系统树附生苔藓植物群落分布格局研究. 植物生态学报, 2000, 24(4): 442-450.

[8] 陈云, 冯佳伟, 牛帅, 许宁, 韩军旺, 叶永忠, 袁志良. 小秦岭自然保护区苔藓植物群落数量分类、排序及多样性垂直格局. 生态学报, $2017,37(8): 2653-2664$.

[ 9 ] 李融, 余成群, 姜炎涁, 刘欣超, 郡小明. 西藏河谷区人工牧草地的苔藓植物群落研究. 干旱地区农业研究, 2010, 28(5): 228-232.

[10] Song S S, Liu X H, Bai X L, Jiang Y B, Zhang X Z, Yu C Q, Shao X M. Impacts of environmental heterogeneity on moss diversity and distribution of Didymodon (Pottiaceae) in Tibet, China. PLoS One, 2015, 10(7): e0132346.

[11] 宋闪闪. 西藏干旱半干旱区丛藓科物种多样性及空间分布的初步研究 [D]. 北京: 中国农业大学, 2015.

［12］谢高地, 张钇锂, 鲁春霞, 郑度, 成升鬼. 中国自然草地生态系统服务价值. 自然资源学报, 2001，16(1): 47-53.

[13] 沈海花, 朱言坤, 赵霞, 耿晓庆, 高树琴, 方精云. 中国草地资源的现状分析. 科学通报, 2016, 61(2): 139-154.

[14] 孙鸿烈, 郑度, 姚檀栋, 张镱锂. 青藏高原国家生态安全屏障保护与建设. 地理学报, 2012, 67(1): 3- 12.

[15] 李以康, 欧阳经政, 林丽, 张法伟, 杜岩功, 曹广民, 韩发. 高寒草甸植被退化过程中生物土壤结皮演变特征. 生态学杂志, 2015,34 (8) : 2238-2244.

[16] 李小娟, 张莉, 张紫萍, 王冬, 李英年, 李茜, 宋明华, 李以康, 周华坤, 杨永胜. 高寒草甸生物结皮发育特征及其对土壤水文过程的影 响. 水土保持研究, 2019, 26(6): 139-144.

[17] 徐恒康, 刘晓丽, 史雅楠, 李晶晶, 尔藏太, 索南加, 郡新庆. 生物结皮对高寒退化草地植物群落的影响. 草地学报, 2018, 26(3)： 539-544.

[18] 王静, 魏小红, 龙瑞军. 东祁连山高寒草甸植物抗寒性研究. 草地学报, 2007, 15(6): 537-542.

[19] 中国科学院中国植被图编辑委员会. 中华人民共和国植被图 1: 1000000. 北京: 地质出版社, 2007.

[20] 中国科学院青藏高原综合科学考察队. 西藏苔藓植物志. 北京: 科学出版社, 1985.

[21] Fick S E, Hijmans R J. WorldClim 2: new 1-km spatial resolution climate surfaces for global land areas. International Journal of Climatology, 2017, 37(12) : 4302-4315.

[22] 马宁, Szilagyi J, 张寅生, 刘文涁. 中国陆地实际蒸散发数据集(1982-2015). 北京: 国家青藏高原科学数据中心, 2019.

[23] 徐新良. 中国年度植被指数 (NDVI) 空间分布数据集. 北京: 中国科学院资源环境科学数据中心数据注册与出版系统. 
[24] 刘艳, 曹同, 王剑, 曹阳. 杭州市区土生苔蘚植物分布与生态因子的关系. 应用生态学报, 2008, 19(4) : 775-781.

[25] 王挺杨, 官飞荣, 王强, 吴玉环. 祁连山不同景观类型中苔藓植物物种多样性研究. 植物科学学报, 2015, 33(4): 466-471.

[26] Abay G, Gül E, Ursavaş S, Erşahin S. Substratum properties and mosses in semi-arid environments. A case study from north Turkey. Cryptogamie, Bryologie, 2014, 35(2): 181- 196.

[27] Zander R H. Genera of the Pottiaceae: mosses of harsh environments. Bulletin of the Buffalo Society of Natural Sciences, 1993, 32 : 1- 378.

［28］杨雪伟, 赵允格, 许明祥. 黄土丘陵区藓结皮优势种形态结构差异. 生态学杂志, 2016, 35(2): 370-377.

[29] Jia R L, Teng J L, Chen M C, Zhao Y, Gao Y H. The differential effects of sand burial on $\mathrm{CO}_{2}, \mathrm{CH}_{4}$, and $\mathrm{N}_{2} \mathrm{O}$ fluxes from desert biocrustcovered soils in the Tengger Desert, China. Catena, 2018, 160: 252-260.

[30] Kou J, Wang T J, Yu F Y, Sun Y W, Feng C, Shao X M. The moss genus Didymodon as an indicator of climate change on the Tibetan Plateau. Ecological Indicators, 2020, 113: 106204.

[31] 张元明, 曹同, 潘伯荣. 干旱与半干旱地区苔藓植物生态学研究综述. 生态学报, 2002, 22(7): 1129-1134.

[32] Aboal J R, Fernández J A, Boquete T, Carballeira A. Is it possible to estimate atmospheric deposition of heavy metals by analysis of terrestrial mosses? Science of the Total Environment, 2010, 408(24) : 6291-6297.

[33] Oishi Y, Hiura T. Bryophytes as bioindicators of the atmospheric environment in urban-forest landscapes. Landscape and Urban Planning, 2017, 167: 348-355.

[34] 杨逸畴, 李炳元, 尹泽生, 张青松. 西藏高原地貌的形成和演化. 地理学报, 1982, 37(1): 76-87.

[35] Wang X T, Niu B, Zhang X Z, He Y T, Shi P L, Miao Y J, Cao Y N, Li M, Wang Z P. Seed germination in alpine meadow steppe plants from central Tibet in response to experimental warming. Sustainability, 2020, 12(5): 1884.

[36] 姚帅臣, 王景升, 丁陆彬, 包小婷, 李超, 王形, 刘文婧, 李妍妍. 拉萨河谷草地群落的数量分类与排序. 生态学报, 2018, 38(13)： 4779-4788.

[37] 张堰青, 周兴民. 海北高寒草甸植物群落的数量分类和排序. 植物生态学与地植物学学报, 1992, 16(1): 36-42.

[38] Wang C T, Cao G M, Wang Q L, Jing Z C, Ding L M, Long R J. Changes in plant biomass and species composition of alpine Kobresia meadows along altitudinal gradient on the Qinghai-Tibetan Plateau. Science China Life Sciences, 2008, 51(1) : 86-94.

[39］卢慧, 丛静, 刘晓, 王秀否, 唐军, 李迪强, 张于光. 三江源区高寒草甸植物多样性的海拔分布格局. 草业学报, 2015, 24(7)：197-204.

[40] Chen S B, Slik J W F, Gao J, Mao L F, Bi M J, Shen M W, Zhou K X. Latitudinal diversity gradients in bryophytes and woody plants: roles of temperature and water availability. Journal of Systematics and Evolution, 2015, 53(6) : 535-545.

[41] Wang J, Vanderpoorten A, Hagborg A, Goffinet B, Laenen B, Patiño J. Evidence for a latitudinal diversity gradient in liverworts and hornworts. Journal of Biogeography, 2017, 44(3): 487-488.

[42］王景升, 姚帅臣, 普穷, 王志凯, 冯继广. 藏北高原草地群落的数量分类与排序. 生态学报, 2016, 36(21): 6889-6896.

[43] Purevdorj T S, Tateishi R, Ishiyama T, Honda Y. Relationships between percent vegetation cover and vegetation indices. International Journal of Remote Sensing, 1998, 19(18) : 3515-3519.

[44] Löbel S, Dengler J, Hobohm C. Species richness of vascular plants, bryophytes and lichens in dry grasslands: the effects of environment, landscape structure and competition. Folia Geobotanica, 2006, 41(4) : 377-393.

[45] Ingerpuu N, Liira J, Pärtel M. Vascular plants facilitated bryophytes in a grassland experiment. Plant Ecology, 2005, 180: 69-75.

[46] Xu W X, Gu S, Zhao X Q, Xiao J S, Tang Y H, Fang J Y, Zhang J, Jiang S. High positive correlation between soil temperature and NDVI from 1982 to 2006 in alpine meadow of the Three-River Source Region on the Qinghai-Tibetan Plateau. International Journal of Applied Earth Observation and Geoinformation, 2011, 13(4): 528-535.

[47] 张江, 袁旻舒, 张婧, 李函微, 王洁仪, 张贤, 鞠佩君, 蒋海波, 陈槐, 朱求安. 近 30 年来青藏高原高寒草地 NDVI 动态变化对自然及人 为因子的响应. 生态学报, 2020, 40(18): 6269-6281.

[48] Wu J P, Gong X Y, Yao X X, Casper D P. Plant communities responding to grazing pressure by sheep in an alpine meadow. Translational Animal Science, 2020, 4(2): 1174-1181.

[49] 杨晓霞, 任飞, 周华坤, 贺金生. 青藏高原高寒草甸植物群落生物量对氮、磷添加的响应. 植物生态学报, 2014, 38(2)：159-166. 